九州大学学術情報リポジトリ

Kyushu University Institutional Repository

\title{
On the design of laboratory scale apparatus for electrokinetic soil decontamination under open- flow condition
}

Wada, Shin-ichiro

Laboratory of Soils, Division of Bioresources and Environmental Sciences, Graduate School of Kyushu University

Ryu, Takashi

Laboratory of Soils, Division of Bioresources and Environmental Sciences, Graduate School of Kyushu University

\section{Darmawan}

Laboratory of Soils, Division of Bioresources and Environmental Sciences, Graduate School of Kyushu University

Umegaki, Yuki

Laboratory of Soils, Division of Bioresources and Environmental Sciences, Graduate School of Kyushu University

https://doi.org/10.5109/24295

出版情報：九州大学大学院農学研究院紀要. 43 (3/4)，pp.479-487，1999-02. Kyushu University バージョン：

権利関係 : 


\title{
On the design of laboratory scale apparatus for electrokinetic soil decontamination under open-flow condition
}

\author{
Shin-Ichiro Wada, Takashi Ryu, Darmawan and Yuki Umegaki* \\ Laboratory of Soils, Division of Bioresources and Environmental Sciences, Graduate \\ School of Kyushu University, Fukuoka 812-8581, Japan \\ (Keceived Septemer 22, 1998 and accepted November 6, 1998)
}

\begin{abstract}
We devised an experimental apparalus to simulate the electroosmotic and hydraulic flow of water during electrokinetic soil decontamination process. The apparatus is an open box with electrode compartments at the both ends and a central compartment in which soil sample is packed. A laminated wire gauze-nylon nel was used as cathode-cum-scparator. The opening of the wire gauzc should be $>1 \mathrm{~mm}$ to let evolved gas escape frecly. The cathode compartment was filled with water and a graphite rod immersed whereir was used as the anodc. The draining conduit was attached to the cathodic end at a position lower than the water table in the anore compartment. Inder this setup, the clectroosmotic and hydraulic flow contributes to the water flow through the soil. To evaluate the electroosmotic flow, the flow under zero electric field was subtracted from the total water flow. Expcriments with a soil with mixed nineralogy showed the subtraction method gave fairly reproducible results with respect to the rate of electroosmotic flow.
\end{abstract}

\section{INTRODUCTION}

By passing a direct current between paired electrodes inserted in moist soil, soil solution flows toward cathode and ionic solutes in soil solution travel toward oppositely charged electrodes. The convective flow of soil solution and the movement of ions are referred to as electroosmosis (EO) and electromigration, respectively (Hunter, 1981). Extensive studies have been carried out to utilize these electrokinctic phenomena to remove contaminants from soils (Acar and Alshawabkeh, 1993). These studies showed that the electrokinetic soil decontamination technology is advantageous in that it can process contaminated soils in situ and that the cost for processing is relatively low (Schultz, 1997). However, the studies also revealed the need for further research to overcome some shortcomings and increase efficiency (Acar and Alshawabkeh, 1993) before it is implemented in the field.

Many researchers have been conducting laboratory scale experiments to solve the problems, e. g., hydrolytic precipitation of migrated cationic heavy metals near the cathode (Zhonming et $a l ., 1997,1998$ ) and to increase the recovery of contaminants (Yeung et al., 1996; Puppala et al., 1997; Coletta et al., 1997) etc. In most of these experiments, soil or clays were packed in columns, saturated with water or conducting solutions and a DC is applied on the both ends via metal or carbon electrodes (Grundl and Reese, 1997). The experimental apparatus using a packed column is convenient for realizing saturated flow throughout the soil body and for regulating the contribution of

* present addiress: Lepartment of Water Resources Engineering, Lund Lniversity, Box 118, S-221 00 Lund, Sweden 
hydraulic flow of soil solution. On the other hand, it has a difficulty in letting gases generated by electrolysis of water escape and it needs consolidation in packing a soil to avoid void formation due to shrinkage of the soil. Probably due to the entrapment of gases at electrode/soil interfaces, the reproducibility in electrokinetic flow rate is not necessarily high (Grundl and Reese, 1997). In addition, the experimental results from the colurm experiments give less straightforward information for designing field experiments because the soil surface is open to the atmosphere in the field and unsaturated flow may prevail at least in upper part of the soil. Recently Kubo and Kawachi (1997) used open boxes with packed polluted clay samples in model experiments for electrokinetic removal of $\mathrm{Cu}, \mathrm{Pb}$ and $\mathrm{Cr}$. In their experiment, however, the reproducibility in flow rate cte. was not exarmined.

In the present study, we designed an experimental apparatus, which is suitable to simulate field processes and free from gas cntrapment at electrodes. The prepared apparalus was tested in terms of the reproducibility in electrokinetic flow rate and the gas problem.

\section{REQUIRREMENTS ANI) SOME THEORETICAI CONSIDERATION}

Fig. 1 shows a basic installation expected in in situ electrokinetic soil decontamination practices. The cationic contaminants migrate toward the cathode while anionic contaminants migrate toward the anode. At the same time, soil solution conlaining neutral contaminants are transported by electroosmosis to the cathode and drained in the cathodic well. To compensate the clectroosmotic drainage and keep the soil conductive, a dilute electrolyte solution should be supplied from the anodic well or from soil surface. Since the soil solution undergo gravitational flow, the cathode and the cathodic woll should be deeper than the anode and anodic well to collect the neutral contaminant quantitativeiy. To effect the combined hydraulic and electroosmotic flow, the cathodic well is better to be emptied out, e. g., by pumping.

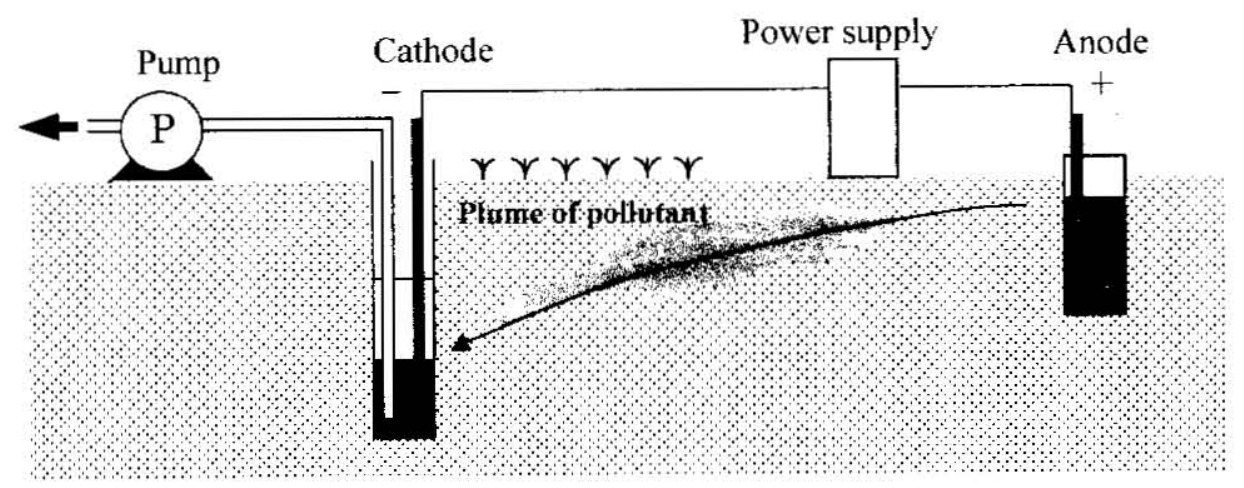

Fig. 1. Schematic diagram of possible electrode arrangement in field implementation of electrokinetic soil decontarrination technique. 
To simulate the flow in an environment depicted in Fig. 1, the experimental apparatus should be an open box, in which a soil sample is packed or a prism of undisturbed soil is placed.

Under a saturated flow condition, rods or plates of carbon or any acid- and alkali-resistant metal immersed in anodic and cathodic solutions function as electrodes. Under an open flow condition with an empty cathodic well (Fig. 1), some modification is necded to maintain electric conductance between the cathode and a soil. Because, a gap will be formed between the cathode and a soil by generated gases, resulting in poor electric conductance. To let the generated gas escape without forming a film at the electrode/soil interface, the electrode should be a carbon or metal screen.

Fig. 2 shows a sketch of a devised electrode assemblage, which is made up of a stainless wire mesh lined with flexible nylon cloth. Although larger cffective arca of contact is expected for smaller mesh, it is unfavorable for free escape of the generated gases, particularly when the electrode well is flooded.

Suppose openings of a wire mesh are circular with a radius $r[\mathrm{~m}]$ and the electrode well is flooded, an external pressure of $2 T / r$ is needed to let the generated gas escape from the openings, where $T$ [ $\left.\mathrm{N} \mathrm{m}^{\prime}\right]$ is the surface tension of the flowing solution.

Under an applied DC, the external pressure is generated by electroosmosis and the electroosmotic pressure must overwhelm the cohesion by surface tension. The

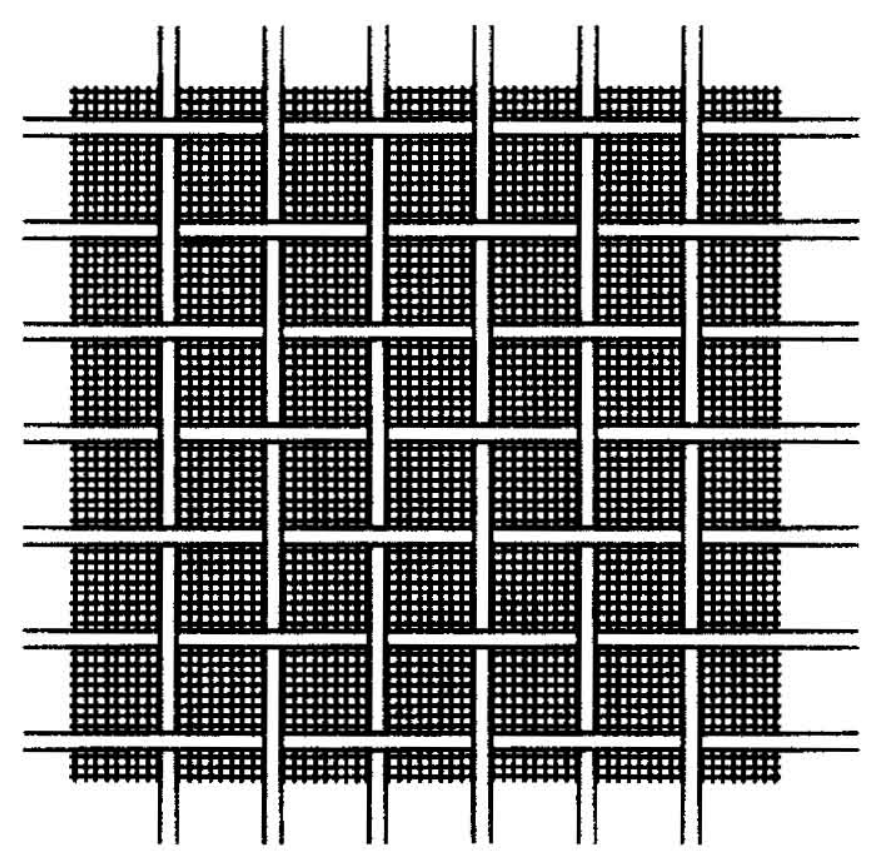

Fig. 2. Sketch of cathode assemblage made up of a coarse metal gauze and finer nylon net. The opening of the metal gauze should be $>1 \mathrm{~mm}$. 
electroosmotic pressure is given by $\left(k_{\mathrm{e}} / k_{h}\right) E$, where $k_{\mathrm{e}}\left[\mathrm{m}^{2} \mathrm{~V} \cdot \mathrm{s}^{1}\right]$ is the electroosmotic permeability, $k_{n}\left[\mathrm{~m}^{2} \mathrm{~Pa}^{-i} \mathrm{~s}^{-1}\right]$ is the hydraulic permcability and $E$ [V] is the electrical potential difference (Casagrande, 1949).

If the electroosmotic and hydraulic permeability of a soil is known, the opening of the wire mesh should be such that satisfies the inequality

$2 T / r<\left(k_{r} / k_{h}\right) E$

The values of $k_{n}$ and $k_{e}$ of soils subjected to electrochemical remediation are around $10^{-16} \mathrm{~m}^{2} \mathrm{~Pa}^{1} \mathrm{~s}^{-1}$ and $10^{-9} \mathrm{~m}^{2} \mathrm{~V}: \mathrm{s}^{-1}$ (Jacobs and Probstein, 1996; Schultz, 1997), respectively and $E$ is usually from 20 to $50 \mathrm{~V}$. The resulting electroosmotic pressure is about 200 to $500 \mathrm{~Pa}$. To satisfy the inequality in (1), $r$ should be larger than about $1 \mathrm{~mm}$.

\section{DESIGN OF APPARATUS AND TESTING METHODS}

The experimental apparatus designed to meet the requirements discussed in the previous section is shown in Fig. 3. The apparatus was made with acrylic plate having a thickness of $5 \mathrm{~mm}$. The dimension of the apparatus was $200 \mathrm{~mm}$ in length, $50 \mathrm{~mm}$ in width and $60 \mathrm{~mm}$ in depth. The anode compartment and central compartinent in which soil sample is placed was separated with a nylon net and the electrode assemblage depicted in Fig. 2 was used as anode-cum-separator. A graphitc rod was placed in the anode compartment.

Throughout the experiment an Ap soil sample from the experimental farm of Kyushu University was used. Prior to use, the soil sample was air-dried and passed through a 2-mm screen and packed in the central compartment of the apparatuses. The organir carbon content of the soil sample was $15 \mathrm{~g} \mathrm{~kg}^{-1}$, the clay content was $246 \mathrm{~g} \mathrm{~kg}^{\prime}$, and the effective cation exchange capacity was $8.7 \mathrm{cmol}(+) \mathrm{kg}^{-1}$. The clay fraction contained vermiculite, kaolin and micaceous minerals.

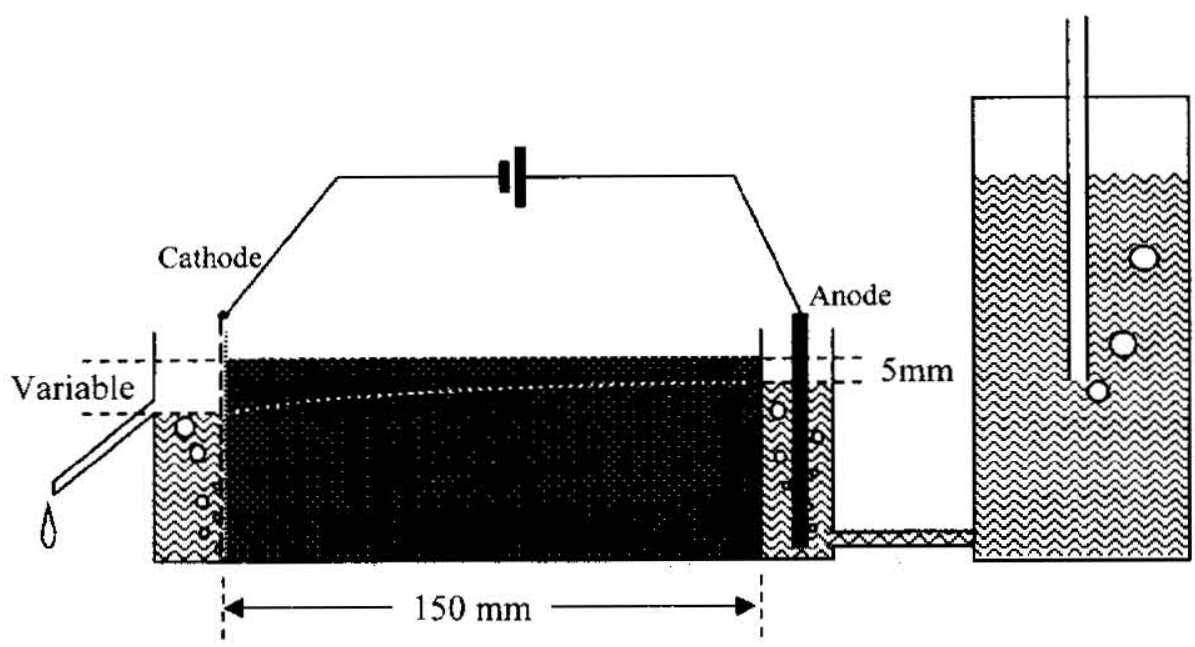

Fig. 3. Schematic diagram of experimental arrangement. The vertical position of the draining conduit is variable. 
By connecting the experimental apparatus packed with air-dried soil to the reservoir of tap water, water raised from the bottom to the surface, saturating the void. When the soil had saturated with water, the water table in the anode compartment was set $5 \mathrm{~mm}$ below the soil surface.

In general, it is extremely difficult to set the vertical position of the draining conduit at exactly the same level to that of the water table in the anode compartment and even a slight upward deviation would cause back pressure to the electroosmotic flow. In addition, the surface tension of water will prevent smooth drainage from the conduit even if it were set at exactly the same vertical position to that of the water table in the anode compartment. Thus, the draining conduit was placed at $>5 \mathrm{~mm}$ below the water table in the anode compartment. With this setup, the electroosmotic flow as well as hydraulic flow contributed the drainage from the conduit.

The drained water was received in a tared polyethylene bottle and weighed periodically to estimate the volume of the effluent. The water was kept drained without voltage load until the hydraulic flow became stationary and then voltage was applied.

All the experiments were carried out in triplicate.

\section{RESUITS OF TFST RUNS AND DISCLESION}

Fig. 4 shows the results of a test run, in which the draining conduit was placed $10 \mathrm{~mm}$ below the soil surface and a voltage of $20 \mathrm{~V}$ was applied $23 \mathrm{~h}$ after the start of the

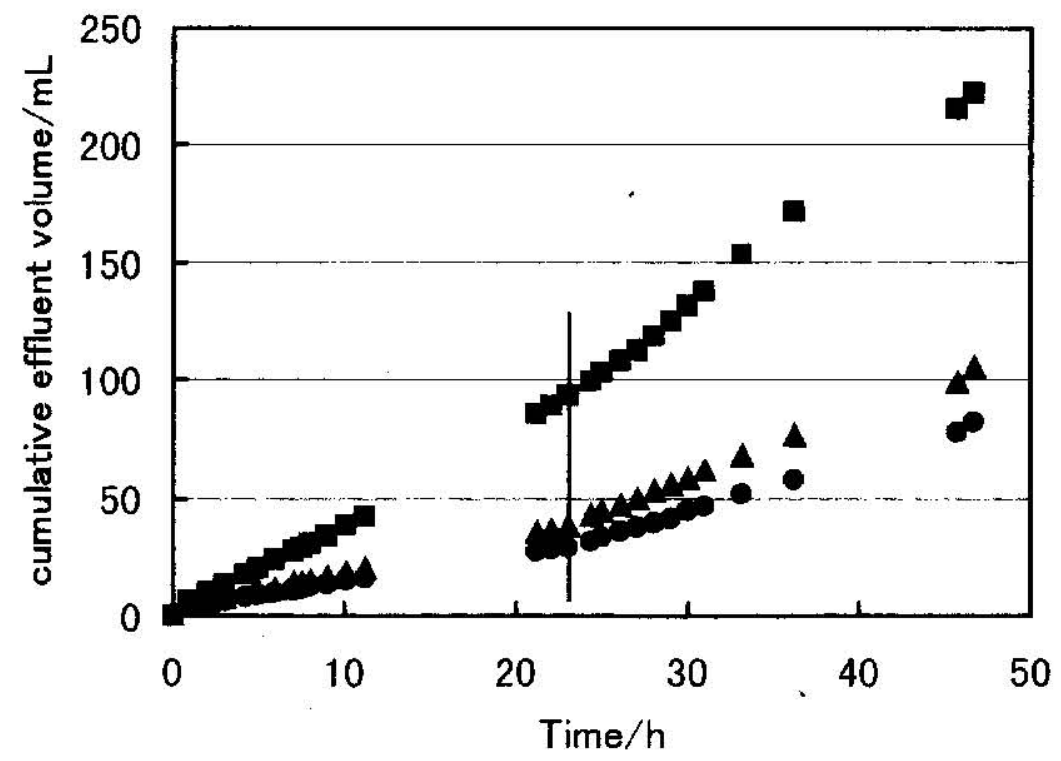

Fig. 4. Cumulative effluent volıme vs. time in an experiment in which draining conduit was placed at $10 \mathrm{~mm}$ below soil surface and $20 \mathrm{~V}$ was applied. The vertical line indicates the voltage application. Three plots are the results from three replications. 
experiment.

Water was drained at a significant rate due to the hydraulic head difference between the anode and cathode before the application of voltage. The plots of the cumulative volume vs. time were linear for time $<23 \mathrm{~h}$, indicating that the hydraulic flow was stationary. However, the rate of the hydraulic flow greatly differed among the replications. This is probably because water mostly flowed through a thin surface layer where the soil would be more heterogeneous in terms of air-entrapment under the hydraulic: regime adopted in this experiment. In addition, the slight difference in the roughness of the soil surface would have affected the flow. The flow rate estimated by linear regression analysis was $1.15,1.58$ and $3.99 \mathrm{~mL} \mathrm{~h}^{-1}$ for the three replications.

After the application of voltage, the volume vs. time plots inflected upwards, indicating that EO contributed the water flow as well. To evaluate the net electroosmotic flow, the linear portion of each plot for time $<23 \mathrm{~h}$ was extrapolated to time $>23 \mathrm{~h}$ and thus predicted contribution of the hydraulic flow was subtracted from the total flow. The results are shown in Fig. 5, in which the calculated net electroosmotic flow was plotted against time after voltage load.

Fig. 5 shows that the predicted net electroosmotic flow was quite similar among three replications at least within $5 \mathrm{~h}$ after voltage load irrespective of big differences in the total flow (Fig. 4). This is a reasonabie resuit since the electroosmotic flow through porous media primarily depends on the surface charge characteristics of the media and the applied electrical potential, while the effects of the size and shape of pores are relatively small (Casagrande, 1949; Hunter, 1981). This experimental result suggests that it is possible to evaluate the net electroosmotic flow by subtracting the contribution of hydraulic flow.

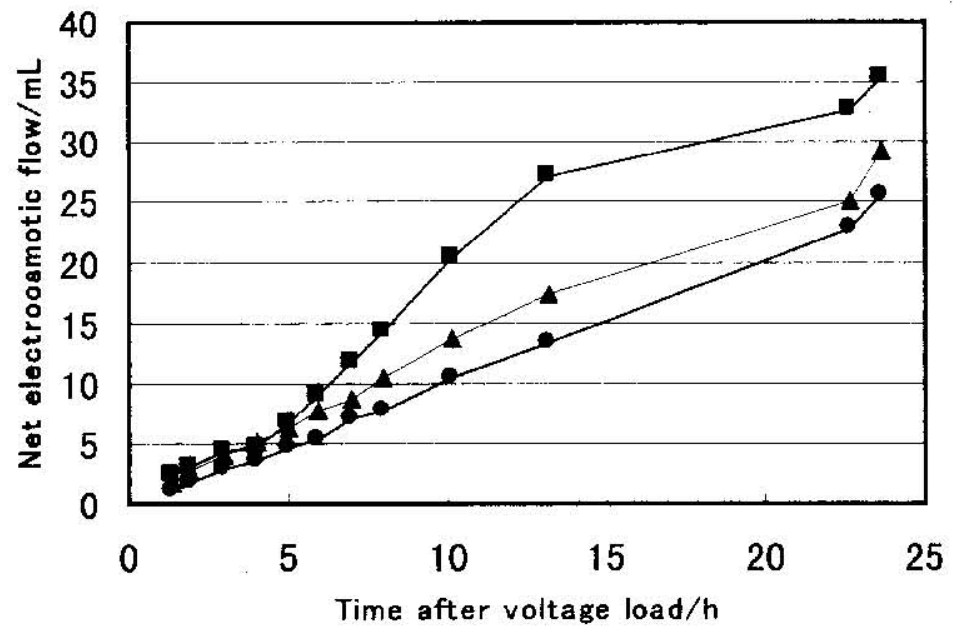

Fig. 5. The net electroosmotic flow vs. time after voltage application calculated from the data in Fig. 4. 
After $5 \mathrm{~h}$ of voltage load and on, however, the difference in calculated electroosmotic flow among the replications increased. This may due to a fluctuation of hydraulic flow rate or heterogeneous change in surface charge characteristics among the replications due to the migration of ions. Nevertheless, the differences in the calculated net electroosmotic flow at about $25 \mathrm{~h}$ after voltage load among the replications were much smaller than those in hydraulic flow. The averaged electroosmotic flow rate estimated by linear regression analysis was $1.06,1.16$ and $1.53 \mathrm{~mL} \mathrm{~h}^{-1}$ for the three replications.

The entrapment of the evolved gas between the anode and soil was not noticeable throughout the experiment.

Fig. 6 shows the result of another test run, in which water was drained from the bottom of the cathode compartment and a voltage of $20 \mathrm{~V}$ was applied after $9.75 \mathrm{~h}$ and then it was switched to $60 \mathrm{~V}$ after $18.6 \mathrm{~h}$.

With a much larger difference in hydraulic potential head of $45 \mathrm{~mm}$ between the anode and cathode compartments, the flow rate was much larger than in the previous experiment (Fig. 5). Although there were significant differences in flow rate among the three replications, the magnitude of the difference was much smaller than that in the previous experiment (Fig. 5). This is probably because water flowed through entire body of the soil under this hydraulic regime. As seen from the straight nature of the plots, the hydraulic water flow was stationary and the flow rate was $8.47,10.09$ and $11.56 \mathrm{~mL} \mathrm{~h}^{-1}$, respectively.

The application of a voltage of $20 \mathrm{~V}$ caused no noticeable increase in flow rate. By applying $60 \mathrm{~V}$, on the other hand, significantly increased the flow rate as seen from the upward inflection of the plots in Fig. 6. The net electroosmotic flow was again estimated

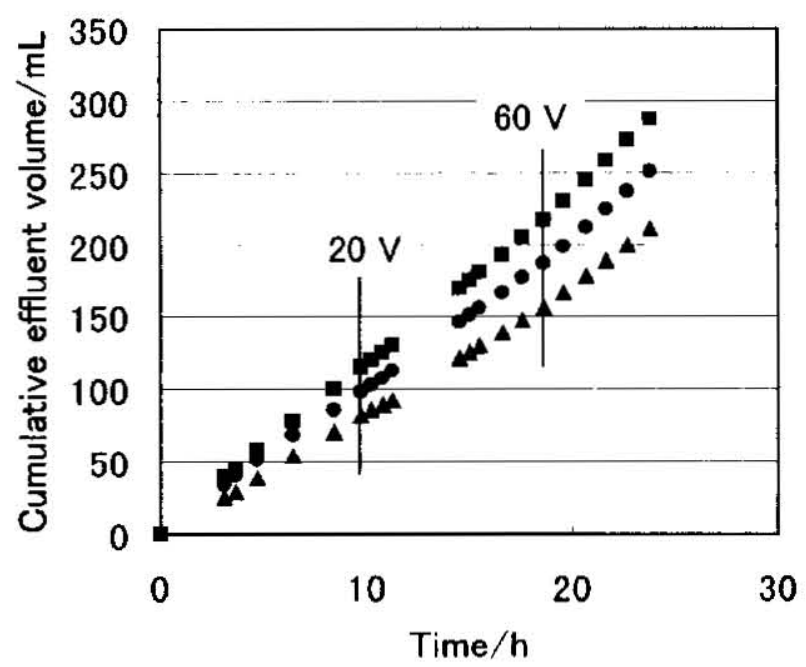

Fig. 6. Cumulative effluent volume vs. time in an experiment in which draining conduit was placed at the bottom. The vertical lines indicate the voltage application. 
in a similar manner used to obtain the results presented in Fig. 5 and the calculated net cumulative electroosmotic flow was plotted against time after applying $60 \mathrm{~V}$ in Fig. 7 . The calculated net electroosmotic flow was quite similar among the replications and linear with respect to elapsed time after voltage load. The linear regression analysis applied to the data plotted in Fig. 7 gave a coefficient of determination of 0.9957 . The flow rates estimated from the slope of the plots were $2.19,2.20$ and $2.29 \mathrm{~mL} \mathrm{~h}^{-1}$ for the three replications with an average of $2.22 \mathrm{~mL} \mathrm{~h}^{-1}$.

The experimental resuits presented in Figs. 4 through 7 show that the open-flow apparatus designed in the present study can be used to simulate the water flow expected in the field implementation (Fig. 1). The drawback of being difficult to simulate only the electroosmotic flow under zero hydraulic head was partly overcome by subtracting the contribution of calculated hydraulic flow.

The theory of EO in porous media (Hunter, 1981) claims that the electroosmotic flow rate is proportional to electrical potential gradient if otherwise the experimental condition is the same. The experimental data given by Casagrande (1949) on various soils and clays approximately satisfies this relation. In the present experiment, the calculated clectroosmotic flow rate increased from $1.06-1.53 \mathrm{~mL} \mathrm{~h}$ ' to $2.19-2.29 \mathrm{~mL} / \mathrm{h}$ ', only about 1.8 times, as electrical potential gradient tripled. This may suggest that the separation of electroosmotic and hydraulic flow by calculation may not have been complete. A possible cause for the deviation from the theoretical prediction is the formation of unsaturated zone near the cathode in the experiment in which water was drained from the bottom of the cathode compartment. To identify the exact cause, further experiments with more homogeneous materials, e. g., kaolinitic or illitic clays, is needed.

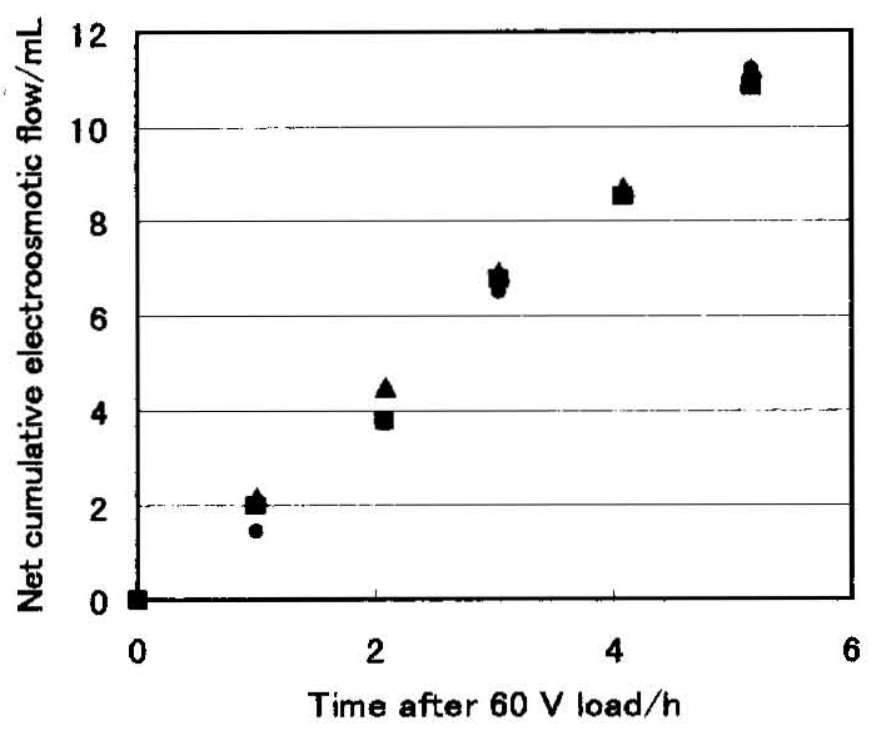

Fig. 7. The net electroosmotic flow vs. time after voltage application calculated from the data in Fig. 6. 


\section{REFERENCES}

Acar, Y. B. and A. N. Alshawabkeh 1998 Principles of electrokinetic remediation. Environ. Sci. Tcchnol., 27: $2638-2647$.

Casagrande, 1. 1949 Electro-osmosis in soils. Geotechnique, 1: 159-177.

Coletta, T. F., C. J. Brucll, D. K. Ryan and H. I. Inyang 1997 Cation-enhanced removal of lead from kaolinite by electrokinetics. J. Environ. Eng. 123: 1227-1233.

Grundl, T. and C. Reese 1997 Laboratory study of clectrokinetic effects in complex natural sediments. J. Hazard. Mater., 55: 187201.

Hunter, R. J. 1981 Zeta Potential in Colloid Science. Academic Press, New York. Jacobs, R. A. and R. F. Probsteir 1996 Two-dimensional modeling of electroremediation. AlChE J., 42: 1685-1696.

Kubo, H. and T. Kawachi 1997 Electrochemical remediation of contaminated soil. Pt. 1 Mobility of heavy metals in small model test. Report of Obayashi Gooperation Technical Research institute, 54: 99-104.

Puppela, S. K., A. N. Alshwabkeh, Y. B. Aca, R. J. Gale and M. Bricka 1997. J. Hazard. Mat.er., 55, 203-220.

Schultz, D. S. 1997 Electroosmosis technology for soil remediation: laboratory results, field trial, and economic modeling. J. Hazard. Mater. s, 55:, 81-91.

Yeung, A. C. -N. Hsu and R. M. Menon 1996 EDTA-entanced clectrokinctic extraction of lead. J. Gootech. Eng., 122: 666-673.

Zhonming, Li., J. -W. Yu and l. Neretnieks 1997 Removal of Cu(II) and Cr(II) from naturally contaminated loam by electromigration. J. Fnviron. Sei. Health., A32: 1293-1308.

Zhonming, Li., J. -W. Yu and I. Nerelnieks 1998 Electroremediation: Removal of hcavy metals from soils by using cation selective membrane. Environ. Sci. Technol., 32: 394-397. 